\title{
Teacher Training Class -Based Through The Example In The Simulator Philosophy Of Mind In Terms Of Quality Evaluation
}

\author{
Mehmet Kasım ÖZGEN ${ }^{1}$
}

In terms of the philosophy of mind in the process of teaching and learning of information to be processed by all the functions of the mind is important. In the learning process when learning of information keeps limited with the memory in terms of mind education leads to quality issues.

Philosophy of mind in terms of teaching and learning together memory, a variety of mental functions such as attention of mind, susceptibility, talent, creativity, thinking, imagination, imagery, analogies, reasoning, logic, problem solving skills, interpretation, coping with crisis, control oneself and knowledge as object, seeing the error, learning from your mistakes to remove, opening itself to new approaches to defeat fear, saving oneself from mental habits chain loop, self-realization mobilizes all together.

A new trend in teacher education proposed here as: Create simulator -based classroom environment. Classroom with simulator targeted come alive with all of the student's mental functions, act through all of his mental energy to focus on the topics learned in a coordinated manner. The main purpose, most similar to the actual state of the subject being taught exhibit in front of the mind and ensure the student's interactive work on the subject. The most appropriate technique allow us to present this environment is simulator based classes.

The essence of this trend as well as the attention to knowledge learned; pay attention to the subject's own mind, show more attention to the mental habits stand out. Thinking skills of the mind in the learning process is not enough alone to be effective. However, emotional and thinking power of the mind both should work effective, in a balanced way at the same time.

Emotions are very active in our learning and decision mechanisms alam. If this mechanism had not been feeling that people learn and make decisions would not be in question. Therefore, in this approach teaching the teacher candidates emotional education in learning and thinking of emotions to run together is very important.

Simulator narrative techniques present the thoughts and feelings most efficient and livingly. Therefore, the most appropriate environment providing the best learning environment is simulator based classes. Because in this class environment, information not transmitted through one- dimensional and limited language. On the other hand, mind will be informed versatile and all functions of mind activated interactively in the most likely real information environment.

The main purpose of the learning in the simulator class is having experience all kinds of situations encountered. Observing the mind in learning, teachers and students will have learned how to use their minds at the same time. In this approach, people will learn to observe yourself from the inside and empathy skills will make it easier. In the classical teaching methods, mind always has the habit of seeing itself through an outside data, so mind be itself always through someone else.

The mind realize its faults only while walking through in its own way and so can learn new things a more permanent way. Make mistakes and learn to draw lessons from the mistakes is the best teacher of the mind. The mistakes while learning best occurs in simulator classes' environment. Therefore, in the classical trend teachers are focused on truths and information, this new approach focused on crisis, omissions and errors. Our minds can never

\footnotetext{
1 Assis. Prof., Cumhuriyet University, Faculty of Education, mehmetkozgen@hotmail.com
} 
learn permanent without pain. Any error on the simulator will make a real experience can provide us like we made a mistake

Therefore simulator based classes will be environments that providing students learning own mistakes easier. Mind learns permanent and high quality when experienced the situation like real. Teaching and learning actually means to have a mind learning to minimize errors, solving problem with error self- guided. Human can learn own mistake in an environment close to the most appropriate. This environment is the simulator classroom environment. 